\title{
Recognition marks and correlation principles of single sand bodies in distributary channel of shallow delta plain
}

\author{
Tingting $\mathrm{He}^{1, \mathrm{a}}$, Xin $\mathrm{Tan}^{1,2, \mathrm{~b}}$, Dongxu $\mathrm{He}^{3, \mathrm{c}}$ and Chao $\mathrm{Yu}^{4, \mathrm{~d}}$ \\ ${ }^{1}$ School of Energy Resources, China University of Geosciences, Beijing, 100083, China \\ ${ }^{2}$ Sinopec International Exploration \& Production Corporation, Beijing, 100029, China \\ ${ }^{3}$ Shengli Production Plant, Shengli Oilfield Company, Dongying, Shandong, 257000, China \\ ${ }^{4} \mathrm{Nanpu}$ Institute of Geology, Jidong Oilfield Company, Tangshan, Hebei, 063200, China \\ ahtt10502@163.com, btanxin200300666@126.com, 'c18905468956@126.com, \\ dychao2013@petrochina.com.cn
}

Keywords: shallow delta plain, distributary channel, single sand bodies, superposition patterns, recognition marks, correlation principles.

\begin{abstract}
Distributary channel is the main type of sand bodies in shallow delta plain. Based on logging geology, sedimentology, sequence stratigraphy and development geology, we systematically analyzed single sand body in the compound distributary channel of shallow delta. Shallow delta plain has well-developed large interconnected and banded compound distributary channel sand bodies. Detail characterization of single sand body reveals that there are 5 main superposition patterns, including overlapping, multi-boundaries, single-boundary, juxtaposition and isolation. We summarize 8 recognition marks of single sand body for vertical timing and lateral boundary recognition. Moreover, 6 correlation principles of single sand body are proposed. By using this model, totally 56 single sand bodies were recognized in the first member of Putaohua oil formation of central Xingshugang oil field and the reasonability of division and correlation of single sand bodies was verified in late production .
\end{abstract}

\section{Introduction}

Most of the old oil fields in the east of China are shallow delta depositional systems, which have now entered a stage of high water cut after years of water injection development. Shallow delta is usually formed in terraces and epicontinental of shallow water and relatively stable structure, or depression lake basin of flat terrain and the overall slow subsidence, and most sediments are distributary channel sand bodies [1-4]. Distributary channel energy of shallow delta plain is strong, and channels are frequently migrated, resulting in lateral and vertical superposition of sand bodies in different periods, which produced a large area of complex compound distributary channel sand bodies. A wide range of thick channel sand bodies in plane are often formed by superposition of various single sand bodies.

Single sand bodies are continuous in vertical and lateral, but existing shale or impermeable interbed [5] with other vertical or lateral sand bodies. Its interior is largely a separate flow system [6]. Because of the complexity of the connectivity between different single sand bodies and differences of itself in the physical property, the reservoir heterogeneity becomes more complex, which seriously impacts on the relationship between injection and production, resulting in contradictory between dynamic and static, so the recognition and correlation of single sand bodies are of great significance in late producing. Based on compound distributary channels, this paper systematically analyzes superposition patterns, and summarizes recognition marks and proposes correlation principles of single sand body, which provides the basis for identifying the internal single sand body of compound distributary channel, and lays the foundation for the remaining oil research and increasing reserves and production of old oilfields. 


\section{Superposition patterns of single sand bodies}

There are 5 main superposition patterns between single sand bodies (Table 1), including overlapping, multi-boundaries, single-boundary, juxtaposition and isolation. Among them, there are sand connected and disconnected in overlapping pattern. Accomondation sediment supply and ratio (A/S) impacts spatial superposed patterns [7]. When the A/S ratio is low, sand bodies were superimposed with each other in vertical, resulting the sedimentation mainly showing vertical accretion and lateral accretion is complementary. The diversity of sedimentary microfacies has been reduced, and sand bodies mainly show overlapping pattern with connected, multi-boundaries or single-boundary, which increases sand connectivity in vertical and lateral. Conversely, when the A / S ratio is relatively high, lateral accretion and aggradation are the dominated sedimentary patterns, increasing the diversity of sedimentary microfacies, and the juxtaposition, overlapping with disconnected and isolation are the mainly superposed patterns.

Table 1 Superposition patterns of single sand bodies

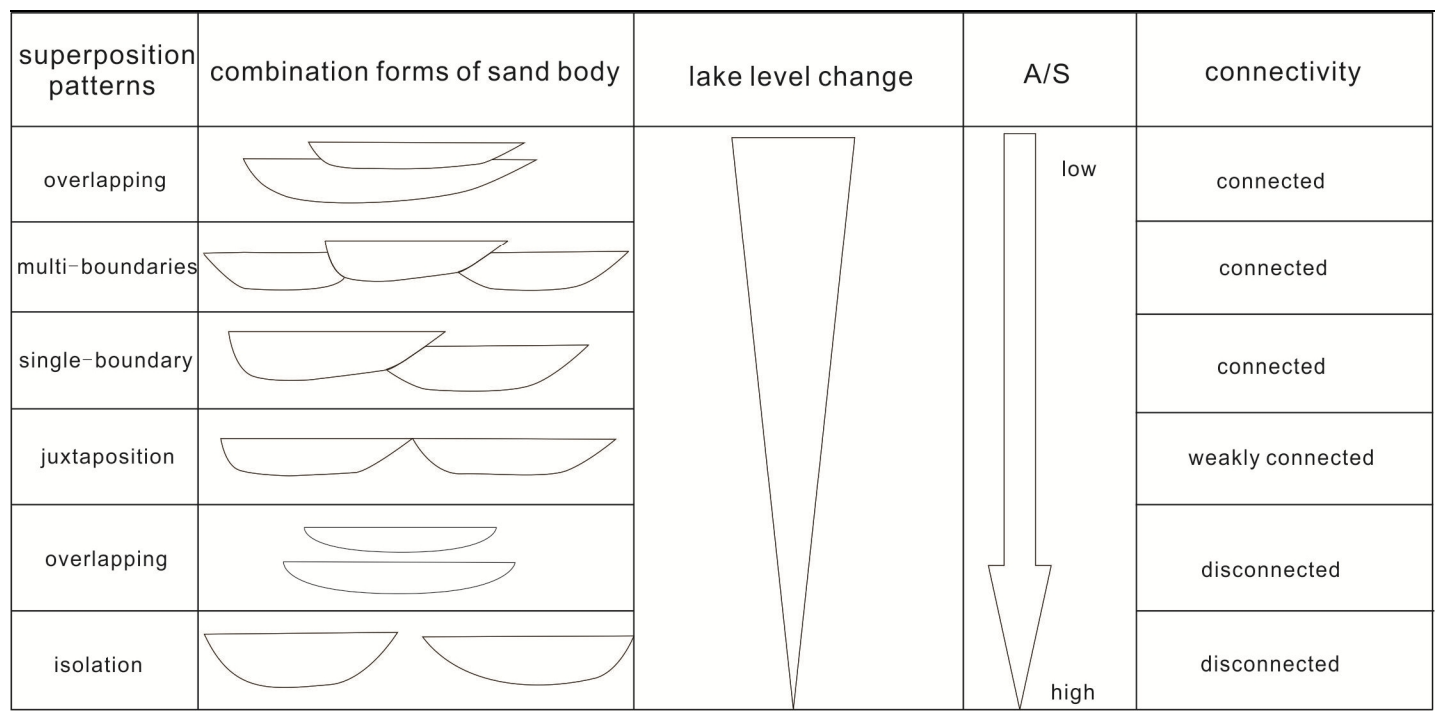

\section{Recognition marks and correlation patterns of single sand bodies}

We summarize 2 vertical timing marks and 6 lateral boundary recognition marks. Mud interlayer or calcareous interlayer can be used to identify single sand bodies of different periods in vertical. In lateral, we usually recognize the boundary of single sand bodies from abandoned channel, discontinuous interchannel deposition, sand bodies thickness difference, logging curves morphology changes, channel elevation difference and sand bodies thick-thin-thick changes.

Correlation patterns of single sand body are mainly described as follows:

(1)Typical marks determination

Marker bed generally refers to widely distributed stable sedimentary layer with significant characteristics in lithology and electrical property. Marker bed represents a standard isochronous surface which formed in a very short time. During the study of clastic rock, marker bed usually is the widely distributed stable mudstone. In carbonate rock, marker bed generally is the marlstone and biologic limestone. Identifying and flattening the marker bed help to determine the correlation isochronism, which reduces tectonic influence.

(2)Bankfull sand correlation

Sedimentary thickness of channel with full sequence reflects the bankfull depth of ancient river deposition, and the top surface reflects the flooding surface of bankfull flood deposition. Top surface of the same channel sediment should be the isochronous surface and substantially parallel with the mark bed. Namely, the distance from top surface of the same channel sediment to the mark bed should roughly equal. But the distance from top surface of channel sediments depositing in different periods to the mark bed should not be the same. So as far as possible to find box-shaped thick sand, and there 
has obviously mudstone at the top (no river erosion on the top surface), and it can be regarded as the same channel sediments. During equal elevation correlation, we should not just identify channel forming period based on elevation difference, the impact of abandoned channel interference and differential compaction should also be paid attention to.

(3)Channel scale control

Outcrop measurement is the most intuitive and authentic way to establish quantitative knowledge base of channel scale, with detectability, accuracy, completeness, and other characteristics. Usually well-exposed channels, and continuous tracking, easy field observation channels are used to observe and measure. Outcrop measurement is generally chosen in study area, or other areas where the geological background is similar. For example, some outcrop was measured, when sand thickness is less than 1.5 meters, width-thickness ratio is greater than 60:1. When sand thickness ranges from 2 to 5 meters, width-thickness ratio is around 30:1. Greater than 5 meters sand bodies are often multi-periods channels, width-thickness ratio is less than 20:1.Generally speaking, the greater sand body thickness, the smaller width-thickness ratio, and the trend is obvious.

(4)Migration modes are different in parallel and vertical directions of source

Migration modes of branch channels are constrained by main channels, and are different in vertical direction of source and in parallel source direction(see Fig.1). Connectivity of the channel sand body in parallel source direction is better than that in vertical direction of source. There are three migration modes in vertical direction of source: migrating and swing in the same direction (see Fig.1a), bifurcation and diffluence in the opposite direction (see Fig.1b), convergence and stack together (see Fig.1c). In parallel source direction, migration mode is downstream and slow progradation (see Fig.1d).

a)

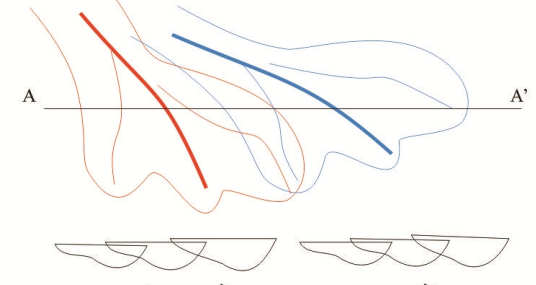

c)

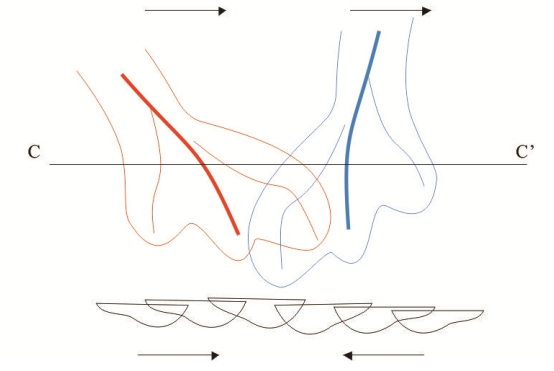

b)

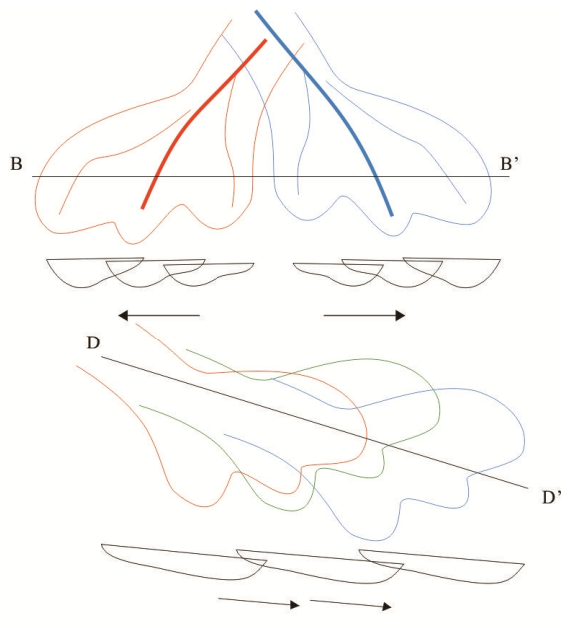

Fig.1 Migration modes of branch channels in parallel and vertical directions of source

(5)Phase sequence grading principle

Phase sequence grading principle is to follow the Walter phase sequence. There is only one center in one channel, and the thickness is gradually thinned to both sides. Meandering river and braided river are the most common in fluvial facies, and distributary channels of delta plain also have the characteristics of the river, so there are braided and meandering distributary channels in delta plain. Hydrodynamism of the braided distributary channel is stronger than that of the meandering distributary channel. From braided distributary channel to meandering distributary channel, the phase sequence changes and the energy of channel gradually weakens.

(6)Dynamic data verification

The above constraint and correlation methods are still a lot of uncertainty during recognition and correlation of single sand body. If we rely solely on the logging curves to judge the channel type, so without taking into account the logging curve shape is different in different positions of channel. If we are overreliant on the equal elevation correlation, the single sand body may be divided too thin, thereby undermining the original appearance of sediments. If we are overreliant on the 
width-thickness ratio, connectivity between channels is difficult to be determined. Therefore, relying on the tracer to monitoring water flooded layers of oil and water wells, we can solve these problems and verify the reasonability of recognition and correlation of single sand bodies. Tracer is easily soluble in water. Injection wells tracer monitoring technique refers to the delivery of tracer in injection wells, tracking and detecting it. Not only can determine the thickness of water flooded layers and permeability, but also we can determine the connectivity between oil and water wells, thus guiding and validating single sand bodies correlation.

\section{Application of recognition and correlation of single sand bodies}

Take the first member of Putaohua oil formation of central Xingshugang oilfield for example, the study area has well-developed large interconnected and banded compound distributary channel sand bodies. Based on the superposition patterns, applying recognition marks of single sand bodies, the different periods of single sand bodies in vertical and boundaries in lateral are identified. Finally, according to 6 correlation principles, reasonability of recognition and correlation of single sand bodies was verified.

According to this research idea, 56 single sand bodies are divided in the first member of Putaohua oil formation. Meandering distributary channels have well-developed near the source, and braided distributary channels have well-developed far away from the source. The single sand bodies all show NW-SE banding distribution. Reliability of the division result of single sand bodies in this study area was confirmed in the late development effect.

\section{Conclusions}

The following conclusions may be drawn according to the results obtained in the present study:

(1)Based on distributary channel sand bodies, 5 main superposition patterns between single sand bodies are summarized, including overlapping, multi-boundaries, single-boundary, juxtaposition and isolation. And there are sand connected and disconnected in overlapping pattern.

(2) 2 vertical timing marks and 6 lateral boundary recognition marks are summarized. Furthermore, 6 correlation principles of single sand bodies are proposed, including typical marks determination, bankfull sand correlation, channel scale control, migration modes difference in different source directions, phase sequence grading principle and dynamic data verification. By using this research idea, single sand bodies of the first member of Putaohua oil formation of central Xingshugang oil field are recognized, and the reasonability of division and correlation of single sand bodies was confirmed in late development.

\section{References}

[1] Donaldson A C: The Geological Society of America. Vol.148 (1974), p.47-48.

[2] Horne J C, Baganz B P: AAPG Bulletin.Vol.62 (1976), p.2377-2411.

[3] Stanley K O, Surdam R C: Journal of sedimentary Petrology. Vol.48(1978), p.557-573.

[4] Postma G: Terra Nova. Vol.2(1990), p.124-130.

[5] Li Xingguo: Microfacies and Micro-tectonic of Terrestrial Reservoir (Petroleum Industry Press, Beijing 2000), p.23-46, In Chinese.

[6] Li Lili: Daqing Petroleum Institute. (PhD Thesis 2009), p.9-15, In Chinese.

[7] Yu Xinghe: Oil and Gas Reservoir Sedimentology of Clastic Rock (Petroleum Industry Press, Beijing 2008), p. 50-52, In Chinese. 